\title{
Approaches and Strategies for Choice of Actions in Self-Paced E-Learning in the Workplace
}

\author{
$\underline{\text { doi:10.3991/ijac.v2i1.618 }}$ \\ A. Wiklund-Engblom \\ Åbo Akademi University, Vaasa, Finland
}

\begin{abstract}
This study is investigating variations of strategic behavior for choosing content and actions in an e-learning course in the workplace. The aim is to provide an increased understanding of differences in how and why learners manage an e-learning environment. Learning needs are related to how we as e-learners develop strategies for navigating and manipulating the content and the environment. Analyses in the present study are guided by the assumption that intentions represent our approaches for choosing content (why we do something), while actions taken represent strategies for choosing content (how we do something). How we manage a learning space has to do with our choices of content, which are based on our intentions for learning.
\end{abstract}

Index Terms - approaches, strategies, choice of content and actions, workplace e-learning.

\section{INTRODUCTION}

The purpose of my research is to find variations in learners' intentions for how to choose content and strategies to manage the learning space. Intentions are seen as cognitive and affective triggers for developing strategic behavior for e-learning. Emphasis is placed on the difference between approaches and strategies in choosing content in a self-paced e-learning course. My understanding of this difference can be summed up like this: Why we do something, the intention behind our actions, equals our approach towards something [1]. Whereas, how we do something, the nature of our actions, equals our strategies [2].

The ability for self-directed learning is an important asset for e-learners [3], especially if a course is self-paced without the traditional support of a teacher/trainer. The content and course features a learner chooses to access will move him/her forward in the course work where the environment in itself is the mediative factor [4]. There is a reciprocal relationship between the environment, the learner, and his/her self-regulation of behavior [5; 6]. A novice e-learner needs to develop affective, cognitive, and behavioral self-regulation techniques [7] in order to adapt to new ways of learning.

This research is based on two assumptions: the first is that intentions behind choices of content reveal the character of affective-, cognitive-, and physical approaches and strategies for learning [7]; the second is that the way we manage within an e-learning environment is the process of our learning, and that our process of learning is closely related to the actual learning outcome [1]. Thus, how we are able to integrate new knowledge from e-learning has a lot to do with our approaches and the strategies we use for managing the learning space.

When asking learners directly what kind of strategies they were using in taking the self-paced e-learning course, they usually referred to having no specific strategy. How we learn is often an intuitive and subconscious process [8]. However, while listening to how they discussed the intentions behind their choices of content within the course several variations in approaches and strategies for choosing content and actions could be detected.

\section{METHODS}

Research questions are: What kinds of intentions are directing their choices of content? (Why they take certain actions.) What is the nature of their strategic behavior for managing the learning space? (How they take actions.)

At two test periods (2003 and 2004) two groups ( $\mathrm{N}=10$; 7) of male e-learners, novice to e-learning, were individually tested in a media laboratory (iDTV lab at Åbo Akademi University, Vasa, Finland) while taking an elearning course related to their workplace. The course subjected to study was under development during the test period. It was improved with regard to learner feedback for the second test group. Hence the groups were confronted with slightly different course version. A mixed methods approach was used to collect data (observations, video recordings, screen recordings, surveys, interviews, psychophysiological measuring, and eye-tracking). Results reported in this paper are based on data from video-stimulated recall interviews, in which screen recordings served as a stimulus for discussing a testpersons course work. The interviews were recorded and transcribed by the researcher.

While analyses of data from observations gave an idea of how the test population managed the environment as such, and their needs on a more technical level, it revealed nothing about the learners' intentions for their actions [3]. On the contrary, interpreting their intentions and cognitive standards based on observations proved to be misleading in many ways. This could be noted from making an integrated worksheet of data collected per person, in which the interviews, interview interpretations, narrative of course work based on observations, and observation interpretations where all lined up for each screen in order to get an overview of a person's total learning profile. Therefore, it was evident that the interviews were critical for investigating their intentions and actions for learning.

An inductive approach was used to analyze variations of qualities of the 17 interviews. All interviews were treated equally, regardless of group belonging, since the aim was not to find differences between the two groups, 
but to find the extent of variations in how and why learners chose content and actions for learning. The interviews were coded in N'Vivo, which is a well-suited computer program for approaching qualitative data inductively. It allows you to play around with data and build categories that are either hierarchically or horizontally related, and also to endlessly manipulate structures of categories until you feel that the data is saturated.

\section{RESULTS}

I started out with a category named Web-Management under which several subcategories where made. One of them was called Choice of Content Strategy. Here, all statements pertaining to why and how they managed the learning space strategically were collected. 106 references were found to be fitted for this node. These could further be categorized into several subcategories. While reading through the statements carefully, I noted down answers to the why-question and the how-question for each statement. By doing that, the difference between approaches and strategies became obvious. A choice of content or action could entail several approaches and sometimes even several strategies.

The strategies and approaches found pertaining to how and why test persons accessed content are by no means exclusive by norm. Any single person showed multiple strategies and approaches while studying the course. However, it is beyond the scope of this paper to measure quantities and correlations of strategies. The purpose is, merely to present variations of approaches and strategies for choice of content and actions within the learning space. I will describe these approaches and strategies more closely in the following.

\section{A. Approaches: Why Learners Take Certain Actions}

While looking at why people take certain actions for learning, a number of variations of qualities of our intentions were found. Fifteen approaches were found, which were categorized into five primary categories: constraint-based, precondition-based, affective, contentbased, and web-management approaches. Table one illustrates these five categories of approaches for choosing content and actions as well as the fifteen approaches. All fifteen approaches are illustrated through interview excerpts below.

\section{1) Constraint-Based Approaches}

These approaches involve factors that somehow limit us in our choices of developing strategic behavior, and thus, how we choose content and actions in our course work for e-learning.

\section{a) Time Constraint-Based Approach}

The e-learner adapts his way of working and choice of content according to his own time frame, the time limits within the course or his workload. One person explained how he made selections of content based on his uncertainty of the extent of the course, and the fact that he did not know how much time he would need to complete it: "The time... I didn't know how extensive it would be, how much course work I had to do. So I didn't follow these links. I only read the text that was there. [12-4]"
TABLE I.

Approaches to CHOOSING CONTENT AND ACTIONS IN SELF-PACED ELEARNING

\begin{tabular}{|c|c|}
\hline 1) & Constraint-Based Approaches \\
& - Time Constraint-Based \\
& - Environmental Constraint-Based \\
& - Physical Constraint-Based \\
\hline 2) & Precondition-Based Approaches \\
& - Experience-Based \\
\hline 3$)$ & Affective Approaches \\
& - Safety-Based \\
& - Interest-Based \\
& - Monvenience-Based \\
\hline 4$)$ & Content-Based Approaches \\
& - Patching \\
& - Pragmatic \\
& - Preparatory \\
\hline 5$)$ & Trial-and-Error \\
\hline
\end{tabular}

\section{b) Environmental Constraint-Based Approach}

The e-learner's way of doing the course work is affected by the surrounding environment; its demands and disturbances. This is evident in the following statement: "On a normal workday, I would not have been so effective and gone through everything... here were no disturbances. [06-3]" This person felt that the laboratory environment enabled him to concentrate more than his own office environment would have allowed. In the test situation, he had the possibility of concentrating without disturbances, and thus, could choose to go through all of the course content without having to make any selections.

\section{c) Physical Constraint-Based Approach}

Reading on the screen and taking own decisions for learning demands both motivation and concentration. One test person had only slept four hours prior to taking the elearning course. This fact of sleep deprivation affected his ways of working in the course. "When taking a course like this, you have to be rested [...] in a normal lecture you will get the information although you're not looking at the lecturer. But here you have to read it yourself. For this you have to be [alert]. [12-4]" He felt that the e-learning environment demanded alertness of him on a different level than traditional training would.

Other physical constraints discussed involved the use of the mouse with the same hand as you would normally use for taking notes. This limits you, and you might choose not to take any notes because of that.

\section{2) Precondition-Based Approaches}

These involve an e-learner's habits, prior experiences and prior knowledge affecting how he behaves in the course work.

\section{a) Experience-Based Approach}

The e-learner transfers his ways of doing from other computer-based environments. He takes actions based on prior experiences of how he is used to working with computers, opening documents, etc. One person said: 
"You're so used to opening all pdf-files and attachments in e-mails and in the information-channel. You open it automatically to look what it is. [14-4]" For this person it was a habit to check everything out on the screen. He noted that this habit came from his ways of working with e-mails and other computer-based information.

\section{b) Prior Knowledge-Based Approach}

The e-learner bases his choice of content and actions on his prior knowledge of the content. Either so that he chooses to look more closely at things he does not know in order to fill gaps, or that he chooses to look at things that he can build on from what he already knows, because it is more interesting. One person did not follow a number of links and explained it like this: “... because I already know what they are all of those things. [01-3]" He skipped the links because he felt them being unnecessary for him due to his prior knowledge.

Another person discussed a topic he knew something about, related to the content, and then justified his choice of links by saying. "It was fun to see what this looks like on $a$ Z. [10-3]" He chose the information that gave him added information regarding what he already knew, simply because it interested him.

\section{3) Affective Approaches}

The affective approaches tell about your intentions on an affective or emotional level. For instance, you prefer to feel safe in your choices of content, or you base your choices solely on interest. This also includes how you motivate yourself, and whether you take the easy road, which is the most convenient to you.

\section{a) Safety-Based Approach}

The e-learner takes actions aiming for trying to avoid anxiety evoking scenarios. He wants to feel safe, and stay with what he already knows. He wants to stay within structures he has experienced before. While skipping the practice questions, one person explained: "I was thinking that it might be a terribly long questionnaire [...] and how I would then be able to come out of it and back to the course. [10-3]" He chose not to take certain content because he was afraid to get lost in the web-based environment, and to face something that required lots of effort. Choosing not to take this particular content, felt like a safer choice for him.

\section{b) Interest-Based Approach}

This is the opposite of a safety-based approach, because here, you choose your actions based on interest in the content or curiosity for the environment. The following statement describes how a test person focused more attention towards content he felt was the most interesting: "I looked more closely at this one. It was rather special. [05-3]”

\section{c) Convenience-Based Approach}

You take the easy road, because it is more convenient for you. While being asked what he would do when confronted with a content-based difficulty within the course, one person answered: "Then you would have to take Back and Continue [navigation buttons], and then you wouldn't find your way back, and take all the questions again, or..., that's too much work. [...] If it's possible, you will climb the fence where it's the lowest. Humans are lazy by nature. [01-3]" His solution would be to skip the problem and move on because it would be the most convenient thing to do for him.

\section{d) Motivation-Raising Approach}

The E-learner takes certain actions to raise his motivation to manage the learning situation. One person felt annoyed from having to view a difficult table a second time. He needed to raise his motivation and searched for something to tell him how much he had completed thus far. "I noticed that I was pretty close to the end, so that helped [...] had the screen kept up my interest, maybe I wouldn't have gone there [...] I was maybe looking for something to motivate me. [14-4]"

\section{4) Content-Based Approaches}

The intentions a learner has for choosing content are directed towards the content of the course. For instance, how he aims for filling gaps of knowledge, or chooses content that is relevant to his work. But also how he mentally prepares himself - or not - for the course material.

\section{a) Patching Approach}

The e-learner aims for information to fill gaps of knowledge. While asked why he took the second link before the first link, one person explained: "Because I was not familiar with [this]. That's why I was more interested in this one. [04-3]" Here we can see how three approaches are represented in one statement: he wanted to fill his gaps of knowledge (patching), he stated that he was more interested in information he did not know (interestbased and prior knowledge-based).

\section{b) Pragmatic Approach}

The e-learner chooses content based on what he needs for his work. He skips things he feels that he already knows. He skips things he feels are irrelevant to learn/memorize. He does only what he feels is needed in order to pass the course. While asked why he skipped the practice questions, one person explained: "I thought it would be a waste of time for me. [07-3]" Another person with a pragmatic approach said: “... this is very good information when I'm looking for something detailed. But it's not information that should be [...] memorized. [083]" Another person said: "This was something I decided not to read [...] I thought it was not required. [13-4]" Being pragmatic, is to evaluate the information and make choices based on your own needs and opinion about the usefulness of the information, rather than to let the course designer's choice of information form your path of learning. For example, prior knowledge, interest, time constraints are all factors influencing a pragmatic approach towards choices of content.

\section{c) Preparatory Approach}

This involves how the e-learner cognitively prepares for learning the content. The following statement is expressed by a person who is well-articulated in his way of describing his preparatory approach for handling the content: "It's good to have some guidance in your mind, what you think in advance what would be the content of the whole course, then you know it in your mind when you go through the whole text, and ... so you know what should be your attitude of this, what they would like you to learn, and if you need to raise some questions in your mind to yourself, to make it easier to understand [04-3]." 


\section{d) Trial-and-Error Approach}

This is an opposite approach to being preparatory in your ways of approaching the content. It is about having no thoughts or opinions about the content beforehand. The following statement exemplifies a trial-and-error approach for approaching the content: "I didn't know what to expect, so I just started. I just read and started [05-3]." He jumped into the content without any mental preparation for what to expect.

\section{5) Web-Management Approaches}

Similarly to the previous content-based approaches, a distinction between a preparatory approach and a trialand-error approach could be made for how test persons started out in their course work; how they managed the web-based environment.

\section{a) Preparatory Approach}

Having a preparatory approach is about forming a preconception of what you are about to encounter (in this case the e-learning environment), because you want to make sure you get the best out of it. This excerpt illustrates a preparatory approach for handling the structure of the environment: "I thought I would go through everything on the [menu] page, what you could do, and how everything worked, and where it linked [...] before I started the actual course [16-4]." He wanted to prepare himself for all possible ways of managing the web-based environment before getting into the content.

\section{b) Trial-and-Error Approach}

The opposite way of starting out is then again to have a trial-and-error approach towards the e-learning environment. You step into it without preparation, trusting your abilities and that the structure will take you where you need to go. One interviewee discussed his habits of learning to use computers through a trial-and-error approach and how this influenced his attitudes for approaching this course: "Handling something like these things [the e-learning course] are not that tough. It's quite easy. Maybe it's because I've learned all the computers I've had just by using them [17-4]."

\section{B. Strategies: How We Take Actions}

While looking at how people take certain actions in their course work, a number of variations of qualities of strategic behavior were found; i.e. how test persons managed the e-learning environment in concrete ways. Table two shows a variety of ten strategies, divided into two primary categories, of how the 17 test persons chose content and actions in their course work.

The first primary category is content-based strategies. It represents variations of how people used strategies to choose content. The second primary category is webmanagement strategies. It represents how people navigated and manipulated the environment. The ten strategies will be further defined and illustrated by interview excerpts in the text below.

\section{1) Content-Based Strategies}

These are variations of how people used strategies to choose content in their course work. These actions, defined as content-based strategies, had their source in test persons' focus on content as a trigger for doing something.
TABLE II.

StRAtegIES FOR CHOOSING CONTENT AND ACTIONS IN SELF-PACED ELEARNING

\begin{tabular}{|c|c|}
\hline 1) & $\begin{array}{l}\text { Content-Based Strategies } \\
\qquad \begin{aligned} \text { — Selective } \\
\text { — Wall-to-wall } \\
\text { — Key content-based } \\
\text { — Layout preference-based } \\
\text { — Problem investigating } \\
\text { — Problem ignoring }\end{aligned}\end{array}$ \\
\hline 2) & $\begin{array}{l}\text { Web-Management Strategies } \\
\qquad \begin{array}{l}\text { - Linearity } \\
\text { - Exploratory } \\
\text { — Problem solving } \\
\text { — Problem dodging }\end{array}\end{array}$ \\
\hline
\end{tabular}

\section{a) Selective Strategy}

The e-learner is pragmatically selective in his choice of actions, only choosing certain content and features based on his own evaluation of how necessary and interesting they are. Therefore, the selective strategy is based on a pragmatic approach. One person described it like this: "I guess I didn't enlarge it, because it's just a bigger one if you click it. And you can clearly see what you want on this one. [04-3]" He did not access the enlarged image screen, because he found it unnecessary.

\section{b) Wall-to-Wall Strategy}

The e-learner cover everything in the course - he moves from wall to wall - either because he feels it is required, or because he has the habit of looking at everything just to see what it is. The statement "I just keep looking at things. [17-4]" illustrates how one person kept accessing all links, texts, and images, because that was his routine of working with computer-based material.

Another person said: "There is probably someone sitting somewhere checking that I have completed the whole course, and if I leave something out I get an incomplete. So, I might as well take it all and get it over with while I'm at it. [15-4]" He felt it was a wiser choice to cover everything in order to make sure he passed the course according to demands set by the course designer.

\section{c) Key Content-Based Strategy}

The e-learner bases his choice of content on what he thinks is most important. Two examples of this are the following statements: "I read this [the heading] first, because it's a bigger font. Makes me think that it's more important. [04-3]" and "Over there, I was reading text only [...] because there is a lot of text and a very small picture. If there are more details on the picture, then I look. [...So you think if there's a lot of text, then...] ...they want me to read, so I read. [11-4]" The first notes that headings are important, and therefore he reads them first. The second notes that he is looking for density of information in order to find key content.

\section{d) Layout Preference-Based Strategy}

The e-learner bases his choice of content on which layout he prefers, for instance, reading text on screen, reading text printed on paper, or looking at images, etc. "... if there are lots of text, so you have to concentrate on both [images and text]... then you look more at this ... the picture [...] That's how I do it [...] because you get a better understanding from the image according to my 
opinion. [01-3]" The reason he focused more on images, was because he knew that he learns better from images than from text.

\section{e) Problem Investigating Strategy}

When an e-learner is faced with a question, or something he does not understand completely, he searches for the answer by using the resources available in a flexible way. "There were some questions that I couldn't find answers to, although I went back to the text [...] I just ended up doing that. I had not planned on going back. This user jumped back and forth several times between practice questions and the text. He even printed a table with lots of data in order to be able to answer the practice questions.

\section{f) Problem Ignoring Strategy}

This strategy is the opposite of the previous strategy. When asked what he does when facing difficult content, one person answered: "Everything goes so fast in a course like this. Instead of facing problems, you just click and move forward. When there is an option to do so. [01-3]" This person did not bother to find answers to questions raised in his head by the material, since there was an option of avoiding it. So he ignored the questions.

\section{2) Web-Management Strategies}

This refers to how you manage the web-based environment on a more technical level; how you navigate, manipulate, and explore it. But also what you do when you face technical difficulties.

\section{a) Linearity Strategy}

The e-learner follows the structure of the system in a linear way. He is looking for the logic of the structure in order to know how the course designer has planned that you should go through the material. One person said: "The way I used it, was actually almost like reading an electronic book. [13-4]" He took all the screens one after the other in a linear sequence. He also commented: "I wasn't sure [how it worked], but at this point I started to get a hold of the system and I'm continuously clicking this Next-button. [13-4]" He was trying to find and follow the logic of a preset navigation structure.

\section{b) Exploratory Strategy}

The e-learner navigates and manipulates the environment in flexible ways. He does not feel that he is bound by any preset linearity in the structure. His choices of how he is moving around in the web-based environment are pragmatic. He makes his own road based on his own interest and/or needs.

One person skipped all practice questions during the first half of the course. Halfway into the course, he started to take only practice questions, skipping the text. He jumped back and forth between questions and text in order to find answers to questions he got incorrect. He replied: "I thought I would test this [practice questions] a little bit in between. [...] I was aware that I began to take only the questions at this point, but it was not a strategy. [06-3] “ He manipulated the environment in a flexible way in order to pass the final test. The exploratory strategy can be a powerful way of pragmatically aiming at filling your gaps of knowledge by using the resources available as flexibly as possible.

\section{c) Problem Solving Strategy}

The e-learner sees technical problems as something unavoidable in a computer-based environment, and when problems occur he solves them in the best way he can with available resources. For example, there was a bug in the first course version. Instead of giving you the option of choosing the Back-button in case you answered the last question of each chapter incorrectly, you were thrown back to the menu screen. One person solved this problem by quickly clicking through the whole chapter again in order to get to the last practice question. He did this over and over until he got the question correct. "The last question was difficult, because you could not come back for that one [...] then I needed to go through all the section to come back there. [...] But I did not read the text then, just ... [09-3]"

\section{d) Problem Dodging Strategy}

The e-learner avoids technical difficulties or ambiguities as far as possible. If something seems to be problematic to access or manage he simply skips it. One person constantly avoided all links that had a double structure of hyperlinks to open a document. He took the first hyperlink, but chose "cancel" when the second came up. His explanation was: "I didn't dear to try again...in case something terrible should happen (being ironic). [103]" He was dodging problems to stay on what was the safe side according to his judgment.

\section{DISCUSSION}

The results presented in this paper exhibit variations of intentions for choice of content (approaches), and variations for actions taken for choice of content (strategies). Intentions describe why a person does something, while the actions describe how a person does something. Workplace learners $(\mathrm{N}=17)$ novice to elearning were tested in a laboratory environment using mixed methods to collect data. For this part of the study, an inductive approache was used for analyzing data from video-stimulated recall interviews.

Fifteen approaches and ten strategies were found for how and why test persons chose content and actions. The approaches were categorized into five primary categories: constraint-based, precondition-based, affective, contentbased, and web-management approaches. The strategies were categorized into two primary categories: contentbased strategies, and web-management strategies.

It must be noted that several approaches and strategies, although many being contrasting by nature, were often simultaneously present in why people chose certain content and actions. This is perhaps the evidence of life being ambivalent on many levels, and we choose to take actions based on many reasons, feelings, background information and so forth. It is the natural process of consciously and subconsciously having an inner dialog for weighing pros and cons for taking actions. The following excerpt is an example of several approaches and strategies expressed in one statement: "It is important to read headings. If you read a heading that interests you, then you read the text. But if you don't think it's interesting and if you have the option of skipping it [the text], then maybe you skip it. [14-4]" I will dissect the excerpt in order to illustrate the analyzing process. 
How is he choosing content? "It is important to read headings." He is choosing that which he feels is key content (key content-based strategy). Why is he choosing the headings? "If you read a heading that interests you, then you read the text." He is looking for things that interest him (interests-based approach).

The statement continues: "But if you don't think it's interesting and if you have the option of skipping it [the text], then maybe you skip it." How? He is choosing selectively, indicating that he might skip it if he feels that there is a possibility to do so (selective strategy). Why? He is choosing pragmatically, based on interest (pragmatic approach and interest-based approach).

I want to emphasize on the perspective this analysis has of looking at variations of how people choose content and take actions. From this perspective, a person's cognitive strategies for learning are merely a secondary factor as can be seen in the results presented above. However, in the next phase of analyzing data the focus will be placed on variations of their cognitive strategies for learning.

\section{REFERENCES}

[1] F. Marton, D. Hounsell, and N. Entwistle, The Experience of Learning, (Swedish Title: Hur vi lär), Kristianstad: Kristianstads Boktryckeri AB, 1986.

[2] C. H. Olgren, "Learning strategies for learning technologies," in The Strategic use of learning technologies, E. J. Burge, Ed. SF, CA: Jossey-Bass, 2000, pp. 7-16.
[3] A. Wiklund-Engblom, "The Web-Based Learning Process: Facilitators for Developing Strategies for Self-Directed WebLearning," unpublished.

[4] Ra. S. Feuerstein, "Dynamic cognitive assessment and the instrumental enrichment program: Origins and development," in Mediated learning experience: Theoretical, Psychological, and learning implications, A. Kozulin and Y. Rand, Eds. Amsterdam: Pergamon, 2000, pp. 147-165.

[5] A. Bandura, Social Foundations of Thought and Action. A Social Cognitive Theory, N.J.: Prentice-Hall, Englewood Cliffs, 1986.

[6] B. J. Zimmerman, "Attaining Self-Regulation: A Social Cognitive Perspective," in Handbook of Self-Regulation. M. Boekaerts, P. R. Pintrich, and M. Zeidner, Eds. London: Elsevier Academic Press, 2005, pp. 13-39.

[7] C. E. Weinsten, J. Husman, and D. R. Dierking, "Self-Regulation Interventions with a Focus on Learning Strategies", in Handbook of Self-Regulation, M. Boekaerts, P. R. Pintrich, and M. Zeidner Eds. London: Elsevier Academic Press, 2005, pp. 727-747.

[8] J. T. E. Richardson, Researching Student Learning, Buckingham: Open University Press, 2000.

\section{AUTHOR}

A. Wiklund-Engblom is with the Research School for Media, Faculty of Education at Åbo Akademi Unviersity, and also working as a research coordinator at the iDTV lab at Media City, Åbo Akademi University, Vaasa, Finland (e-mail: awiklund@abo.fi).

This article was modified from a presentation at the the International Conference on E-Learning in the Workplace (ICELW2008) in New York, NY, USA, June 2008. Manuscript received 15 July 2008. Published as submitted by the author. 